2001-01-01

\title{
Mass transport by non-linear internal waves on the Malin Shelf
}

Inall, ME

http://hdl.handle.net/10026.1/9730

10.1016/s0278-4343(01)00020-6

Continental Shelf Research

Elsevier BV

All content in PEARL is protected by copyright law. Author manuscripts are made available in accordance with publisher policies. Please cite only the published version using the details provided on the item record or document. In the absence of an open licence (e.g. Creative Commons), permissions for further reuse of content should be sought from the publisher or author. 


\title{
Mass transport by non-linear internal waves on the Malin Shelf
}

\author{
M.E. Inall ${ }^{\mathrm{a}, 1}$, G.I. Shapiro ${ }^{\mathrm{b}, 2}$, T.J. Sherwin ${ }^{\mathrm{a}, *}$ \\ ${ }^{a}$ Marine Science Laboratories, UWB School of Ocean Sciences, Centre for Applied Oceanography, Menai Bridge, \\ Anglesey, LL59 5EY, UK \\ ${ }^{\mathrm{b}}$ P.P. Shirshov Institute, Russian Academy of Sciences, 36 Nakhimovsky Prospect, 117851, Moscow, Russia
}

Received 8 November 1999; received in revised form 8 March 2001; accepted 25 April 2001

\begin{abstract}
Packets of non-linear internal waves (NIWs) were observed with a moored ADCP in the seasonal thermocline at the edge of the Malin Shelf, to the west of Scotland, during August 1995. A wide range of wave sizes was encountered including some that were strongly non-linear. The largest waves had a vertical displacement of about $25 \mathrm{~m}$ (in $145 \mathrm{~m}$ water) and a vertical shear greater than $0.4 \mathrm{~m} \mathrm{~s}^{-1}$ over a depth of $65 \mathrm{~m}$ across the thermocline. In general they propagated toward the ESE, which is south of a line normal to the shelf break, with a phase speed of between 0.54 and $0.60 \mathrm{~m} \mathrm{~s}^{-1}$. Within each packet the direction of the current flow in successive waves veered at a similar rate to that of waves with a tidal frequency. However, large NIWs were only encountered during neap rather than spring tides, so their relationship with the tide is not entirely clear. The first empirical mode dominated the motion, but its shape was often more convoluted than an equivalent baroclinic mode. A two-layer $\mathrm{KdV}$ theory for the mass transport due to the waves, which relates transport to the elevation of the interface and the linear long wave phase speed, is presented. It compares well with the observed transport in the lower layer. None of the waves possessed significant dispersion, so they did not conform to the KdV soliton solution. In a typical NIW packet a lower layer transport of about $5 \mathrm{~m}^{2} \mathrm{~s}^{-1}$ offshore was maintained over a period of about $1.5 \mathrm{~h}$, with a peak of about $20 \mathrm{~m}^{2} \mathrm{~s}^{-1}$. A sustained transport of about $0.3 \mathrm{~m}^{2} \mathrm{~s}^{-1}$ can be attributed to NIWs at the Malin Shelf edge in summer. (C) 2001 Elsevier Science Ltd. All rights reserved.
\end{abstract}

Keywords: Internal waves; Non-linear waves; Mass transport

\footnotetext{
*Corresponding author. +44-0-1248-713808; fax: +44-0-1248-716729.

E-mail address: t.j.sherwin@uces.bangor.ac.uk (T.J. Sherwin).

${ }^{1}$ Present address: UHIP, Dunstaffnage Marine Laboratory, P.O. Box 3, Oban, Argyll, PA43 4AD, UK.

${ }^{2}$ Present address: Institute of Marine Studies, University of Plymouth, PL4 8AA, UK.
} 


\section{Introduction}

The Malin Shelf is situated to the west of Scotland. In common with many other shelf regions it experiences significant internal wave activity in summer. One form of this activity is the internal tide, a low frequency internal wave forced by the barotropic tide. Another form are large high frequency (c 3 c.p.h.) internal waves that can best be explained by invoking nonlinear dynamics. The currents in some high frequency waves observed on the Malin Shelf are the subject of this study. For convenience they will be referred to as non-linear internal waves (NIWs).

There are a number of reasons for studying NIWs. For a start they may affect anthropogenic activities. Vertical oscillations of the thermocline can complicate the acoustic detection of submarines; and the large locally enhanced currents within NIWs can significantly affect the movement of remotely operated vehicles and divers employed in the exploration and extraction of hydrocarbons. From a scientific point of view, the intimate relationship between the internal tide and NIWs may have a bearing on the dissipation of tidal energy and, through their contribution to mixing in the thermocline, NIWs aid the vertical exchange of nutrients and heat near the shelf edge (e.g. the Scotian Shelf, Sandstrom and Oakey, 1995). They may also make an important contribution to sand transport rates (e.g. the Armorican Shelf, Heathershaw, 1985). It is also possible that the mass transport associated with NIWs contributes directly to shelf edge exchange. Huthnance (1995) has suggested that a typical wave packet can contribute about $1 \mathrm{~m}^{2} \mathrm{~s}^{-1}$, which can be the same order of magnitude as other shelf edge processes, such as slope current meanders and upwelling.

Satellite borne Synthetic Aperture Radar (SAR) images reveal NIWs as curved striae on the water surface, with each stria being typically of order $200 \mathrm{~m}$ wide and $50 \mathrm{~km}$ long and having wave crests that appear to radiate away from the shelf break towards the coast (e.g. da Silva et al., 1997). In situ observations show that beneath the surface the seasonal thermocline is thrust far down (over $60 \mathrm{~m}$ in the Celtic Sea, New and Pingree, 1992) by the leading, and often largest, wave. Some packets in the Celtic Sea propagate at speeds in excess of $1 \mathrm{~m} \mathrm{~s}^{-1}$ and have surface currents of similar magnitude. However, taken as a whole, NIW observations suggest that no one description summarises all waves. For example, Halpern (1971) observed a large internal bore in Massachusetts Bay that disintegrated into a large number $(>20)$ of internal waves. More recently, Small et al. (1999b) observed a smaller bore on the Malin Shelf, just north of the observations that are described here, that subsequently disintegrated into about 5 waves. The number of NIWs that form when an internal bore disintegrates depends on the ratio of the parameters of dispersion, non-linearity and dissipation in the water column (Barenblatt et al., 1985). On the Scotian Shelf, packets of between two and four NIWs have been observed (Sandstrom and Elliott, 1984). The NIWs on the Portuguese Shelf, whilst being of similar scale to those on the Scotian shelf, are much wider than KdV solitons (Jeans and Sherwin, 2001). More information can be found in the review of NIWs by Ostrovsky and Stepanyants (1989) who give a good indication of the range of NIWs that can be found world wide.

Many in situ measurements of NIWs have relied on thermistor chains, echo sounders, or other methods of tracer observation. Consequently there has tended to be an emphasis on the vertical elevation of the waves rather than their horizontal velocities. Large amplitude internal 
waves are usually interpreted in conjunction with "weak" non-linear theory (e.g. Holloway et al., 1999). The basic equation of this theory is the $\mathrm{KdV}$ equation, developed over 100 years ago by D.J. Korteveg and G. de Vries. In many cases this equation seems to describe the propagation of the interface quite well (e.g. Konyaev and Sabinin, 1992), although there have been few studies of the currents in the waves. A comparison between NIW velocities and KdV theory in laboratory tank experiments by Walker et al. (1998) gave good agreement for nonlinearity ( $\varepsilon$, see below) up to 0.25 , although the measured velocities fell off significantly above that value.

Theories relating to the generation of NIWs at the shelf edge tend to be restricted to a slice normal to the bathymetry and considering the tidal forcing of a two-layer ocean (both of which may be serious over-simplifications). Maxworthy (1979) suggested that NIWs develop in the thermocline from a lee wave that is set up during the ebb (off-shore) phase of the tidal cycle and propagate on-shore when the tide starts to flood. In a more detailed study Renouard and Zhang (1989) performed experiments in a long non-rotating laboratory tank. They found that the Froude number, $F=U_{\mathrm{T}} / C_{0}$ where $U_{\mathrm{T}}$ is the maximum tidal current and $C_{0}$ is the long wave baroclinic phase speed (both on the shelf), is a good parameter of the problem. With $F<1$ (which applies to the Malin Shelf), an internal tide is formed which develops NIWs in its trough as it propagates across the shelf. When $F>1$, NIWs occur throughout the tidal cycle. The effect of the Earth's rotation is to make all long waves dispersive, and this suppresses the tendency of the internal tide to form NIWs (Gerkema, 1996). Gerkema's numerical solutions to the KdV equation with forcing suggest that if the generation process is weakly non-linear (e.g. at the Celtic Sea shelf edge) then NIWs will emerge from the trough of the internal tide. However, if the process is strongly non-linear then a disintegrating on shore propagating bore will be formed (e.g. as seen in Massachusetts Bay).

Linear theory of internal tide generation at a shelf edge considers the interaction between barotropic tidal currents, stratification of the seasonal thermocline and large changes in bathymetry. Apart from the strength of the tidal currents, a critical parameter is the ratio of the angle of the slope divided by that of the internal tide characteristic, $\lambda$. When $\lambda>1$ the slope is steep (or super-critical) and large internal tides may be generated (with attendant NIWs); when $\lambda<1$ (or sub-critical) the resulting internal tides are small (e.g. Craig, 1987). The internal tide on the Malin Shelf along $55^{\circ} 53.3^{\prime} \mathrm{N}$, south of Sta. S140 (Fig. 1), has been previously studied by Sherwin (1988) and modelled by Sherwin and Taylor (1990). They found that the slope region was marginally super-critical and that an internal tide with an amplitude of about $10 \mathrm{~m}$ in the thermocline propagated onshore with an energy flux that was bigger on springs than on neaps. The largest barotropic tidal current constituent was found to be M2 (period $12.42 \mathrm{~h}$ ), with an onshore amplitude of about $0.14 \mathrm{~m} \mathrm{~s}^{-1}$, although occasionally the sum of the other major diurnal and semi-diurnal constituents can exceed it.

The paper continues with a formal derivation of equations for mass transport and velocity that can be applied to waves with weak non-linearity. There then follows a description of the horizontal velocity structure of the NIWs on the Malin Shelf. Although the details of the observed currents is more complicated than assumed in the theory, the observed and theoretical transports compare surprisingly well. Finally, the implications of the work are discussed. 


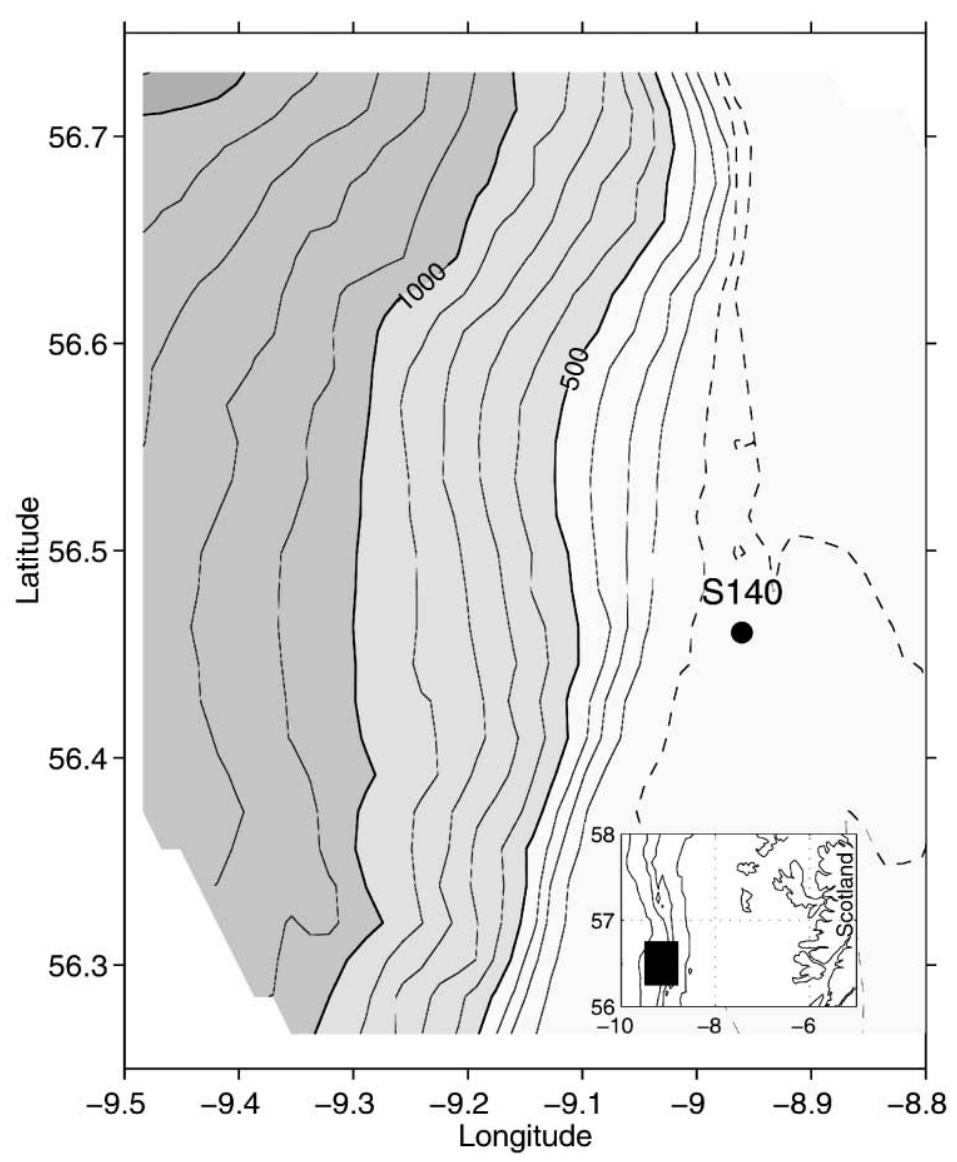

Fig. 1. Bathymetry of the Malin Shelf edge. Inset shows the location in relation to the west coast of Scotland.

\section{Theory}

In this section we provide a derivation of the wave induced mass transport that is consistent with KdV theory for a two layer system. The analytical formulation determines the residual mass transport generated by non-periodic NIWs, and expresses the transport in terms of the interface displacement and its time derivatives at a point location. We consider non-linear long internal waves in a two-layer non-rotating inviscid fluid over a flat bottom where the motion is assumed to be two-dimensional and irrotational (Fig. 2). The barotropic flux is assumed zero. In these circumstances an equation that governs the propagation of waves in the lowest non-linear order of approximation is the $\mathrm{KdV}$ equation

$$
\frac{\partial \xi}{\partial t}+C_{0} \frac{\partial \xi}{\partial x}+\alpha \xi \frac{\partial \xi}{\partial x}+\beta \frac{\partial^{3} \xi}{\partial x^{3}}=0,
$$




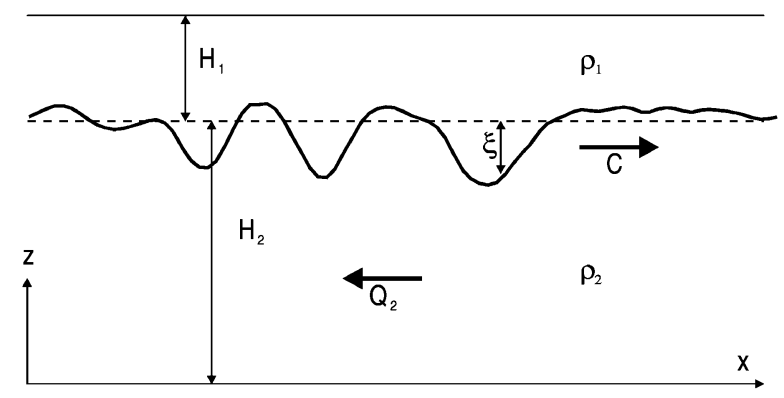

Fig. 2. Schematic diagram of an internal wave train showing the variables used in the text. The wave is propagating to the right with an observed phase speed, $C$.

where $x$ is the distance in the direction of propagation; $t$ is time; and $\xi$ is the interface elevation.

$$
C_{0}=\left(\frac{g^{\prime} H_{1} H_{2}}{H_{1}+H_{2}}\right)^{1 / 2}, \alpha=\frac{3}{2} C_{0} \frac{H_{1}-H_{2}}{H_{1} H_{2}}, \beta=C_{0} \frac{H_{1} H_{2}}{6}, g^{\prime}=g \frac{\rho_{2}-\rho_{1}}{\rho_{2}}
$$

are the phase speed for long (non-dispersive) linear internal waves, non-linearity coefficient, dispersion coefficient, and reduced gravity acceleration, respectively. The density of the upper and lower layers are $\rho_{1}$ and $\rho_{2}=\rho_{1}+\Delta \rho$ respectively; $g$ is gravity; and $H_{1}$ and $H_{2}$ are the undisturbed thicknesses of these layers. Strictly speaking, the KdV Eq. (1) is only valid for $H_{1} \neq H_{2}$ and $\varepsilon \ll 1$, where

$$
\varepsilon=\xi / H_{\mathrm{eq}}
$$

and

$$
H_{\text {eq }}=\frac{H_{1} H_{2}}{\left(H_{1}+H_{2}\right)}
$$

On the Malin Shelf the first restriction $\left(H_{1} \neq H_{2}\right)$ is never violated, but the second $(\varepsilon \ll 1)$ is not always satisfied. However laboratory experiments have shown excellent agreement between observed and KdV predicted elevations (e.g. Kao et al., 1985, in particular their p. 36 and Fig. 10) for a wide range of parameters, including values of $\varepsilon$ that are larger than formally required. A more detailed discussion of the limitations of Eq. (1) and other non-linear wave equations can be found in Ostrovsky and Stepanyants (1989).

Eq. (1) can be compared with the mass conservation equation for the lower layer

$$
\frac{\partial\left(H_{2}+\xi\right)}{\partial t}+\frac{\partial Q_{2}}{\partial x}=0
$$

where

$$
Q_{2}=\int_{0}^{H_{2}+\xi} U_{2} \mathrm{~d} z
$$

is the depth integrated water mass flux, or transport, in the lower layer. Comparison of Eqs. (1) and (4) yields

$$
\frac{\partial}{\partial x}\left(C_{0} \xi+\frac{1}{2} \alpha \xi^{2}+\beta \frac{\partial^{2} \xi}{\partial x^{2}}-Q_{2}\right)=0 .
$$


Since the assumptions behind Eq. (1) are that the non-linear and dispersion terms are much smaller than the linear term, to leading order $\partial \xi / \partial x=\left(-1 / C_{0}\right)(\partial \xi / \partial t)$. With this approximation it is possible to eliminate the $x$ derivatives of $\xi$ in the dispersion term and, to the same order of accuracy, rewrite the third term in Eq. (6) as $\left(\beta / C_{0}^{2}\right)\left(\partial^{2} \xi / \partial t^{2}\right)$.

The present study focuses on the dynamics of wave packets of finite length, so wave motion is assumed to vanish at long distances, i.e. $\xi \rightarrow 0$ as $x \rightarrow \infty$. It is also assumed that there is no shear flow in the limit $x \rightarrow \infty$, so $Q_{2}(\infty)=0$. This yields the equation for the transport in the lower layer, $Q_{2}$, as the sum of the linear, non-linear and dispersion terms

$$
Q_{2}=C_{0}\left(\xi-\frac{3\left(H_{2}-H_{1}\right)}{4 H_{1} H_{2}} \xi^{2}\right)+\frac{H_{1} H_{2}}{6 C_{0}} \frac{\partial^{2} \xi}{\partial t^{2}} .
$$

To the same order of accuracy, the depth average horizontal velocity is, using (5),

$$
U_{2}=C_{0}\left(\frac{\xi}{H_{2}}-\frac{H_{1}+3 H_{2}}{4 H_{1} H_{2}^{2}} \xi^{2}\right)+\frac{H_{1}}{6 C_{0}} \frac{\partial^{2} \xi}{\partial t^{2}} .
$$

Since it is assumed that there is no barotropic flux, the transport in the upper layer has the same absolute value as $Q_{2}$ but is opposite in direction. Thus, the theory expresses transports and velocities in terms of a time varying interface displacement and linear phase speed. It has the considerable advantage that Eqs. (7) and (8) involve neither the non-linear phase speed nor the spatial derivatives of the interface displacement, both of which are difficult to measure accurately in the ocean.

As an aside, there exist steady wave-like solutions to Eq. (1), an example being the internal soliton (a solitary wave) which occurs when the non-linear and dispersion terms balance (see, e.g., Ostrovsky and Stepanyants, 1989). This wave, which has the form $\xi=-\xi_{0} \operatorname{sech}^{2}[(x-C t) / L]$ where $C$ is a non-linear phase speed and $L$ is a scale length, has been widely invoked by oceanographers. An approximate estimate of the transport in a soliton is $C \xi$, which can be shown to be the sum of the linear and non-linear terms in Eq. (7). In contrast to a linear sinusoidal wave, a soliton is a wave of depression (or elevation) only. When the various terms in Eq. (7) are integrated between $\pm \infty$ for a soliton the dispersion term becomes zero but the linear and nonlinear terms do not. For example, on the Malin Shelf the ratio of total non-linear/linear transports is about $0.2 \varepsilon$. By definition, a soliton is only an approximation in the ocean. Eq. (7) is not restricted by the assumptions of the waves being solitons, and it thus seems prudent to use it to examine the transport in real NIWs, rather than to attempt to fit the data to its shape in some arbitrary manner.

\section{Observations}

\subsection{Methods}

The measurement programme was part of the United Kingdom Natural Environment Research Council's (NERC) LOIS/SES programme, an extensive study of exchange processes at the edge of the Malin Shelf (Fig. 1). The relevant observations were made by an RD Instruments $150 \mathrm{kHz}$ Broad Band Acoustic Doppler Current Profiler (ADCP) located at Sta. S140 (56 27.6 N, 
$8^{\circ} 58.0^{\prime} \mathrm{W}$ ) in $145 \mathrm{~m}$ of water approximately $5 \mathrm{~km}$ to the east of the shelf break. The deployment lasted for 19 days from 17 August to 4 September, 1995. The instrument transmits sound along four paths, orientated at $30^{\circ}$ to the vertical, and analyses the Doppler frequency shifts of echoes from acoustic scatterers in the water column. Two minute ensemble averages of horizontal and vertical velocity were made in 25 bins, each extending over $5 \mathrm{~m}$ with centres ranging between 7.5 and $127.5 \mathrm{~m}$. The ADCP relies on sufficient natural scatterers in the water column to create a good return signal and does not always give reliable data, particularly in the highest bin but sometimes also in the lowest one. The instrument software calculates a statistic called "percent-good", based on the proportion of returned pulses in each bin that exceed the signal-to-noise threshold. Data that were less than $80 \%$ good were rejected. If these absent data points had good values adjacent in either time or space, then they were estimated by linear interpolation. The ADCP conducts an internal auditing of its measurements from which it is estimated that the standard deviation error in individual horizontal velocities was about $0.014 \mathrm{~m} \mathrm{~s}^{-1}$.

Additional data were collected by RRS Challenger which held station near Sta. S140 for two periods of $24 \mathrm{~h}$ (on 19-20 and 30-31 August) making a variety of measurements including: profiles of temperature and salinity using a Neil Brown MkIII CTD probe; digital imaging of surface roughness from the ship's X-Band Radar; and profiles of turbulence dissipation. The ADCP and CTD were maintained by NERC's Research Vessel Services and the raw data converted to scientific units by the British Oceanographic Data Centre. The data were subsequently analysed using the Matlab software package and CTD processing made use of the Seawater routines (Morgan, 1994).

\subsection{Three examples of NIWS}

Surface slicks associated with an NIW packet were clearly seen from the ship on 21 August and recorded with the X-band Radar digital capture system. They propagated towards $125^{\circ} \mathrm{T}$ with a phase speed of approximately $0.6 \mathrm{~m} \mathrm{~s}^{-1}$. These waves occurred during a period when large high frequency (greater than 1 c.p.h.) velocity shears - defined as the mean velocity in the upper layer $(7.5-33.5 \mathrm{~m})$ minus that in the lower layer $(67.5-102.5 \mathrm{~m})$ - were observed across the thermocline by the ADCP (19-23 August, Fig. 3). Surprisingly, this period coincided with the small on-shore/ off-shore low frequency (below 1/6c.p.h.) barotropic currents associated with neap tides. There is little evidence of NIWs during the latter part of the month when spring tides prevailed. Although it is not possible to present every wave in detail, the description given below of a few contrasting examples is instructive because it demonstrates that they lacked uniformity.

One of the largest wave packets was encountered during neap tides just before $1700 \mathrm{~h}$ on 19 August. Five of the waves, of which the leading one was the biggest, are shown in Fig. 4, which depicts the horizontal currents in several different ways for clarity. Vertical displacements were computed by integrating the vertical velocity signal, which was highpass filtered above 1 c.p.h. The leading wave had an amplitude of about $25 \mathrm{~m}(\varepsilon \approx 1)$ and arrived about $1 \mathrm{~h} 50 \mathrm{~m}$ after slack water-defined as the time that the on-shore component of the low frequency barotropic current turned off-shore (see Fig. 3) - and about $3 \mathrm{~h}$ after high water (HW) Ullapool $\left(57^{\circ} 54^{\prime} \mathrm{N}, 5^{\circ} 10^{\prime} \mathrm{W}\right)$. By $1700 \mathrm{~h}$ the off-shore component of the barotropic current had reached $0.05 \mathrm{~m} \mathrm{~s}^{-1}$. As the leading wave passed the ADCP the depth of the peak in the forward velocity followed the downward movement in the wave and reached a maximum $\left(>0.5 \mathrm{~m} \mathrm{~s}^{-1}\right)$ a few minutes after 

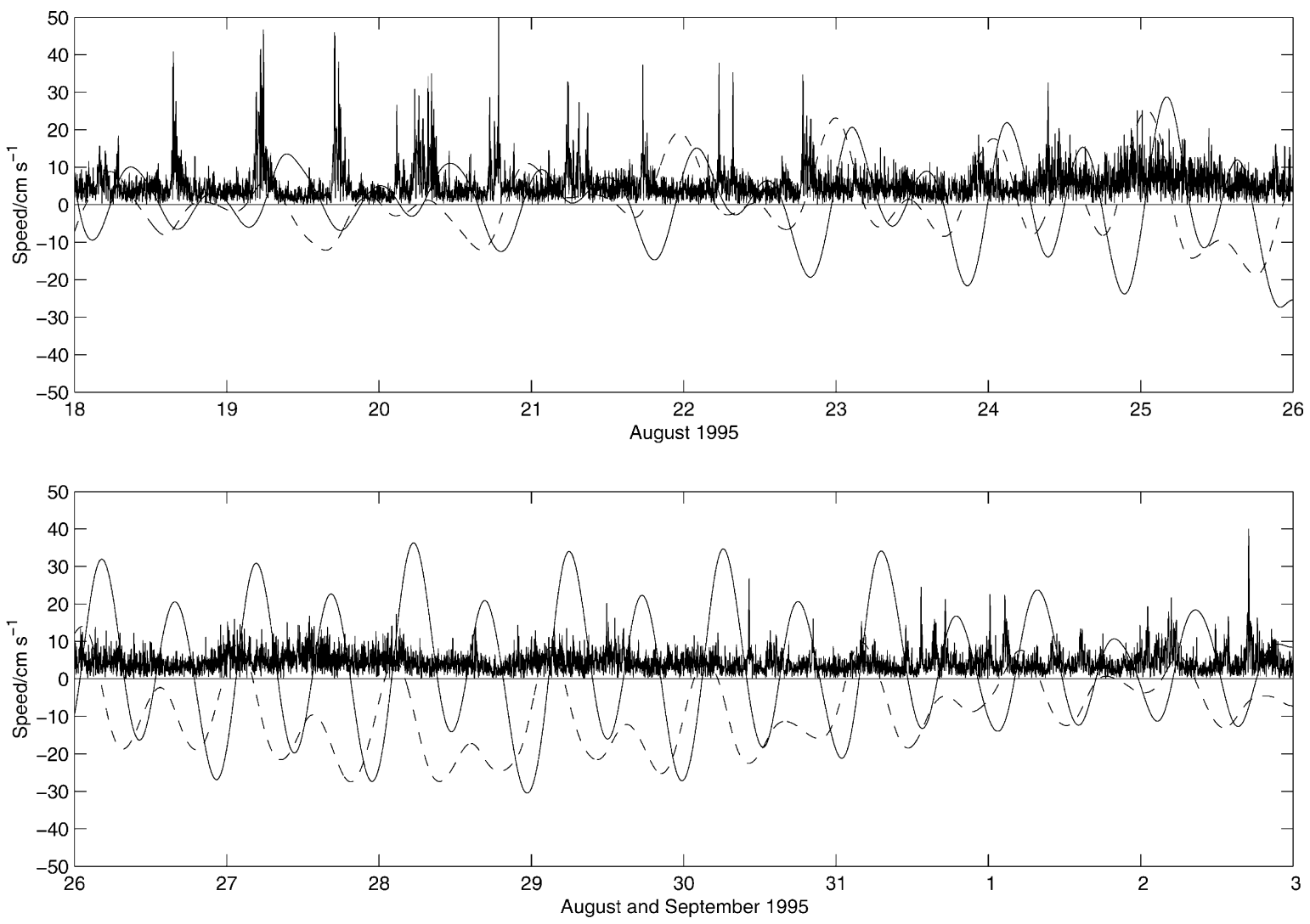

Fig. 3. East-west (plain line, east positive) and north-south (dashed line, north positive) low pass barotropic currents at Sta. S140 during the deployment period. The high frequency curve is the speed of the shear across the thermocline, defined from the average upper layer minus average lower layer velocities.

the wave had reached its deepest excursion (Fig. 4d). The depth of the fastest current below the thermocline was depressed in a similar fashion. The current in the first two waves, which were about $37 \mathrm{~min}$ apart, was aligned towards about $125^{\circ} \mathrm{T}$ (Figs $4 \mathrm{e}$ and f). However, by the time the third wave arrived, only 10 min later, it had turned significantly more southward (towards about $140^{\circ} \mathrm{T}$ ). With the arrival of the fourth and fifth waves (between 1 and $1.5 \mathrm{~h}$ later) it had veered further to about $155^{\circ} \mathrm{T}$. It is not possible to say, from a single moored instrument, whether this implies that the individual waves were actually propagating in different directions, or whether the direction of the strongest currents in each wave was rotating with time as it propagated across the shelf. However, the rotation occurred against a background shear that also rotated anticyclonically, at about $30^{\circ}$ an hour. Since this corresponds to the rate of change of current direction in the internal tide, the latter explanation seems more likely.

On 22 August, starting at $1840 \mathrm{~h}$, four or five smaller waves crossed the mooring at roughly $35 \mathrm{~min}$ intervals (Fig. 5). On this occasion the leading wave arrived about $3 \mathrm{~h} 10 \mathrm{~m}$ after slack water and about $1 \mathrm{~h} 45 \mathrm{~m}$ after HW Ullapool. At this time the off-shore current was about $0.17 \mathrm{~m} \mathrm{~s}^{-1}$. The first four waves were of similar size with a maximum depression of about $12.5 \mathrm{~m}$ 

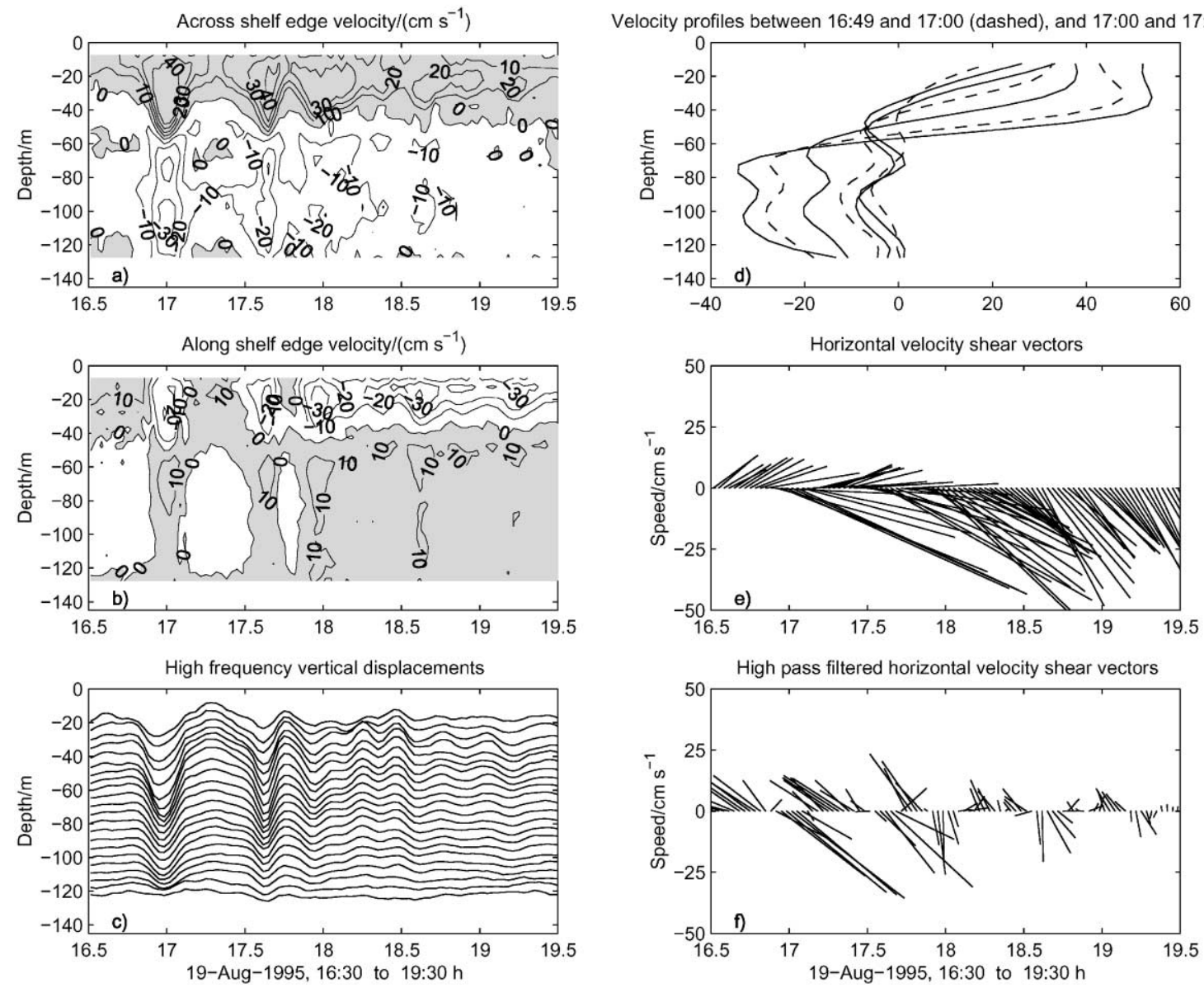

Fig. 4. A packet of five large NIWs $(\varepsilon \approx 1)$ observed on 19 August presented in several different ways for illustration. (a) Unfiltered velocities at $2 \mathrm{~min}$ intervals parallel to $100^{\circ} \mathrm{T}$ across the shelf edge (positive values on shelf), (b) unfiltered velocities parallel to the shelf edge (positive values northward), (c) vertical displacements derived from the vertical velocity signal, highpass filtered above 1 c.p.h., (d) shear profiles at approximately $4 \mathrm{~min}$ intervals during the passage of the first wave - the depth average current has been removed, (e) unfiltered vectors of the shear across the thermocline showing the waves modulating the background shear, (f) shear vectors highpass filtered above $1 \mathrm{c}$.p.h. to show the direction of wave propagation.

$(\varepsilon \approx 0.5)$. Although this amplitude was smaller than on 19 August the waves had larger surface currents $\left(<0.6 \mathrm{~m} \mathrm{~s}^{-1}\right)$, possibly because the surface layer (about $30 \mathrm{~m}$, Fig. $5 \mathrm{~d}$ ) was shallower (c.f. Fig. 4d). Unlike the wave on 19 August, the maximum forward speed in the leading wave remained near the surface although the size of the peak below the interface, at about $60 \mathrm{~m}$, seemed to increase slightly as the thermocline deepened. There appeared to be a very rapid drop in speed near the seabed. The current in the leading wave was directed towards $135^{\circ} \mathrm{T}$, but by the time of the fourth wave it had veered to $165^{\circ} \mathrm{T}$.

The third example occurred at about $0340 \mathrm{~h}$ on 3 September when three waves, about $45 \mathrm{~min}$ apart, were observed (Fig. 6). They arrived about $1 \mathrm{~h}$ before HW Ullapool (0437 h) and about $2 \mathrm{~h}$ 

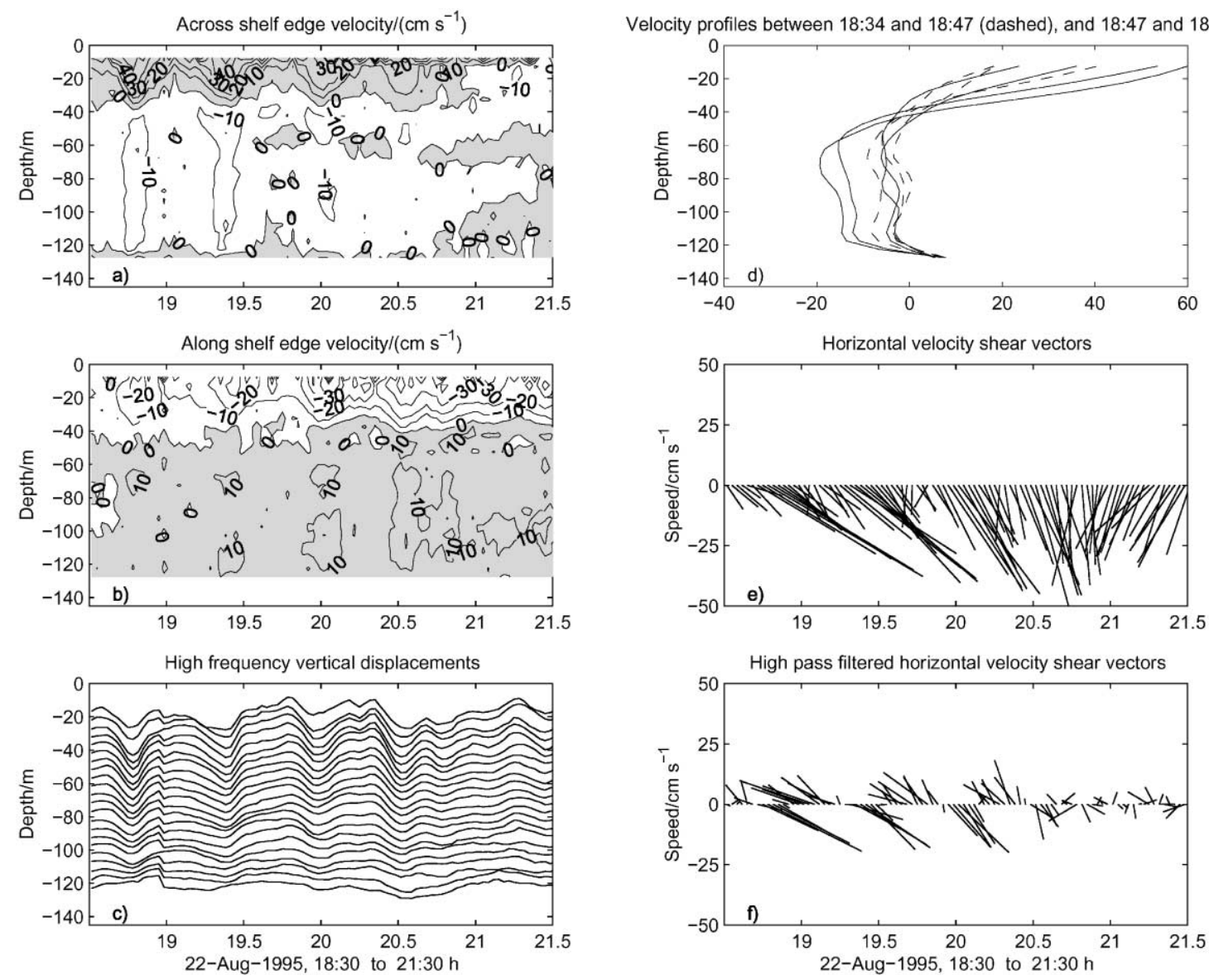

Fig. 5. Four or five smaller NIWs $(\varepsilon \approx 0.5)$ observed on 22 August. Caption as Fig. 4, Note that this time there is very little net return flow beneath the thermocline in the across shelf velocity (e.g. Fig. 5a).

after slack water. This time the leading wave (which is most clearly seen in Fig. 6c) was the smallest. In the second wave $(\varepsilon \approx 0.5)$ the interface dropped about $15 \mathrm{~m}$ but only recovered about $10 \mathrm{~m}$; its currents were directed towards $65^{\circ} \mathrm{T}$, a more northerly direction than in the previous examples (Fig. 6e). There was also a noticeable veer in current direction, towards $100^{\circ} \mathrm{T}$, by the time the third wave arrived. Maximum forward velocities of nearly $0.4 \mathrm{~m} \mathrm{~s}^{-1}$ were typically $20 \mathrm{~m}$ below the surface, whilst below the shear layer the maximum return flow (also nearly $0.4 \mathrm{~m} \mathrm{~s}^{-1}$ ) was about $60 \mathrm{~m}$ above the seabed (Fig. 6d). However a significant part of this shear was due to the low frequency internal tide, and when it is removed the high frequency component shows that the second wave was actually propagating towards $135^{\circ} \mathrm{T}$ (Fig. 6f).

It would appear from these observations, and from other high frequency internal waves not presented here, that there was a significant variability in the waves. Although their size did not seem to be directly related to that of the barotropic currents they tended to arrive between 1 and $4 \mathrm{~h}$ after HW Ullapool which, along with the speed at which the velocity direction veered, implies a degree of correlation with the internal tide. The veering of the current direction in successive 

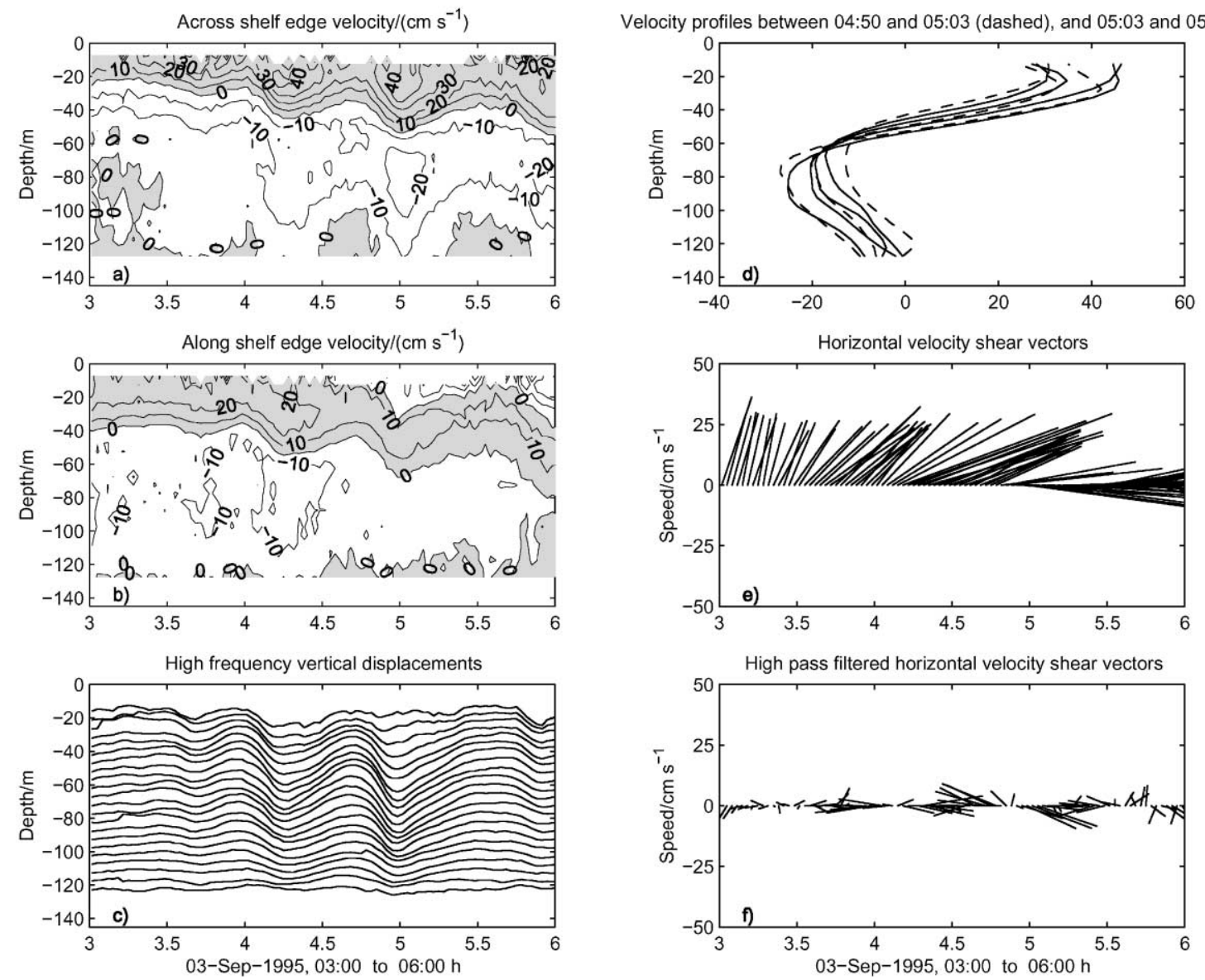

Fig. 6. Three NIWs with a longer period than before, observed on 3 September $\approx \approx 0.5$. Caption as Fig. 4. The background shear dominates the first wave (e.g. Fig. 6e).

waves suggests that the directions of energy propagation and mass transport in the NIWs may be difficult to predict a priori. In addition the vertical profile of the horizontal current in an individual wave was sometimes more complicated than that suggested by its vertical displacement, with the maximum speed being observed just above or below the interface. This phenomenon can also be seen in observations from the Celtic Sea (see figures in New and Pingree, 1992).

\section{Modal analysis}

Since the ADCP made simultaneous observations of vertical and horizontal velocities it should be well suited to investigate the validity of Eq. (7), provided that a consistent way can be found to define the level of the interface at successive time steps. However, in order to improve confidence in the observations it is necessary to check that the velocities are self-consistent (i.e. that they satisfy continuity). In addition, although the internal waves are described here with non-linear 
dynamics, to a first order their vertical structure should be similar to that derived from linear theory. The theoretical structure is discussed first.

\subsection{Baroclinic modes}

Vertical density profiles were obtained from CTD profiles near Sta. S140 on 19 August before the onset of the internal waves (Fig. 7a) and again when they passed under the ship (Fig. 7c). In a horizontally homogeneous and unbounded sea with a flat bottom and general density profile $\rho(z)$, the equation of motion of a sinusoidal internal wave is

$$
\frac{\mathrm{d}^{2} w}{\mathrm{~d} z^{2}}+\left(\frac{N^{2}-\sigma^{2}}{\sigma^{2}-f^{2}}\right) k^{2} w=0
$$

(e.g. Phillips, 1977). Here $k$ is the horizontal wave number of the mode; $\sigma$ is the frequency of the oscillation; and $f$ the Coriolis frequency. The buoyancy frequency squared, $N^{2}$, is defined by

$$
N^{2}=\frac{-g}{\rho} \frac{\partial \rho}{\partial z}
$$

In a finite difference form Eq. (9) can be cast as an eigenvalue problem by specifying $N^{2}$ from Eq. (10) and fixing $\sigma$. The baroclinic modes are then ranked in order of increasing $k$, so that mode 1 has the lowest wave number (and longest wavelength).

The eigenvector of the first baroclinic mode of a 10 min wave, $w_{1}$, was calculated from two averaged density profiles (Figs. 7a and c), resolved at intervals of $2 \mathrm{~m}$, and its velocity mode

computed from $\partial w_{1} / \partial z$ (Figs. $7 \mathrm{~b}$ and d). These modes were both normalised so that $\sqrt{\mu_{1}^{2} \ldots \mu_{\mathrm{P}}^{2}}=$ $2 / 5$, where there were $\mathrm{P}$ elements $\left(\mu_{1}\right.$, etc.) in each mode. The norms were scaled by $2 / 5$ to aid later comparison with EOF modes which were resolved on a $5 \mathrm{~m}$ interval. It can be seen that the vertical position of the zero crossing point of $u$ coincides closely with the local depth of the pycnocline. Furthermore the maximum forward and backward velocities are encountered just above and below the pycnocline respectively, in a manner that is not dissimilar to the profiles presented in Fig. 4d.

\subsection{Empirical modes}

For the vertical and horizontal currents to be self-consistent one would expect their respective eigenvalues to contain similar proportions of energy, and the vertical derivative of the largest $w$ eigenvectors to be the same as the equivalent $u$ eigenvectors (suitably scaled). This is a requirement of the continuity equation, $\partial w / \partial z+\partial u / \partial x=0$, and assumes that $\partial v / \partial y$ is small, which was generally the case.

The empirical modes of horizontal and vertical velocity in individual wave packets were analysed using empirical orthogonal function (EOF) analysis. The method computes the eigenvalues, $\lambda_{m}$, and eigenvectors, $\varphi(z)_{m}$, of an $M \times M$ co-variance matrix with internal elements $a_{i j}$ computed from

$$
a_{i j}=\sum_{n=1}^{N} u_{i}\left(t_{n}\right) u_{j}\left(t_{n}\right)
$$



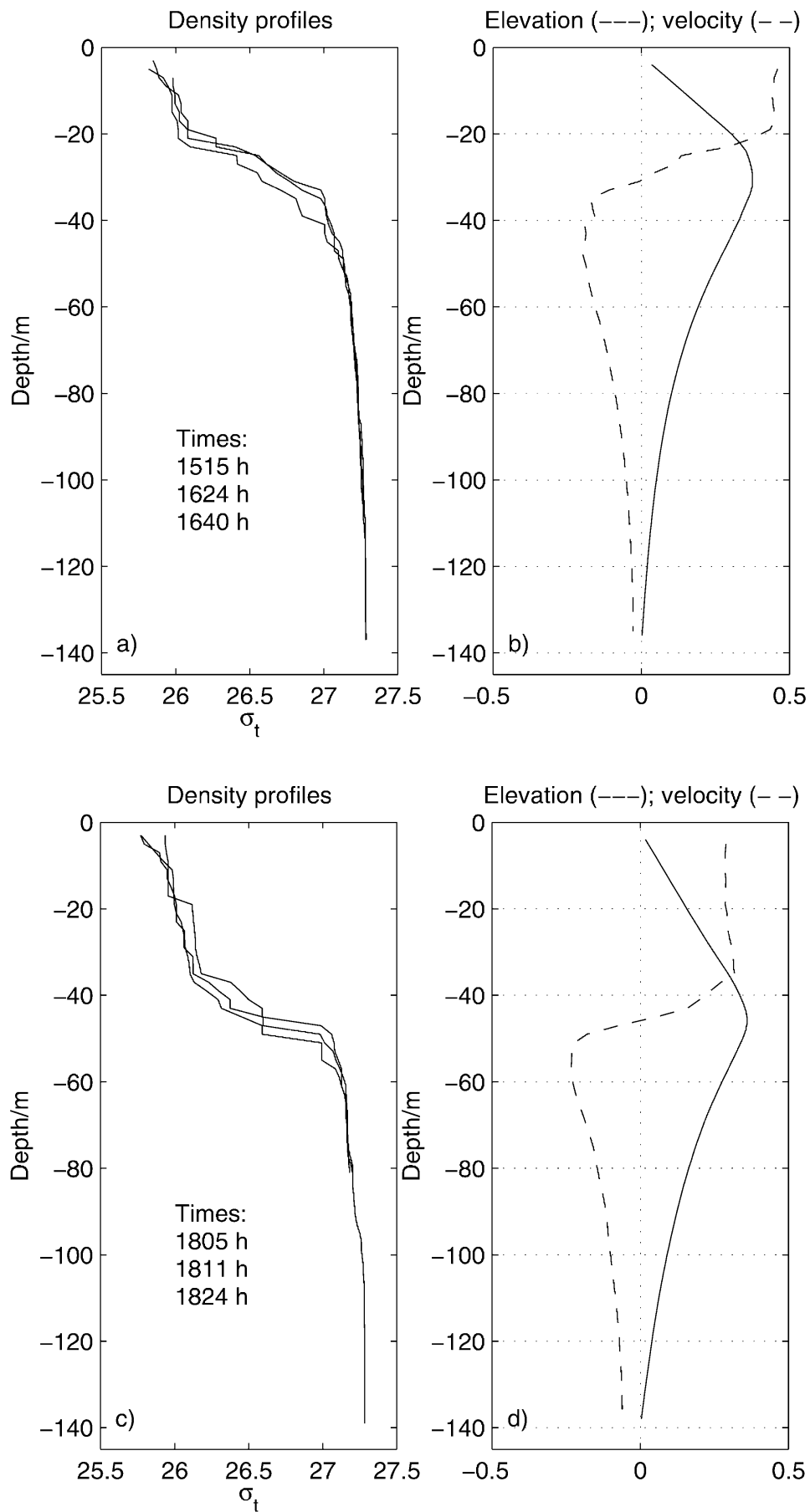

Fig. 7. (a) CTD profiles near Sta. S140 on 19 August before the arrival of the NIWs, (b) first baroclinic mode for a 10 min wave (plain line) and its vertical derivative, representing the equivalent velocity profile (dashed line), (c) as (a), and (d) as (b), but during the passage of the waves. The horizontal velocity mode does not contain all the structure of the equivalent empirical mode (Fig. 8a). 
Here $M$ is the number of bins used by the ADCP (25); $i, j, m=1, \ldots, M ; N$ is the number of observation events; and $u_{i}\left(t_{n}\right)$ is the horizontal velocity in the direction of wave travel at time $t_{n}$ and level $i$. The eigenvectors are normalised so that $\sqrt{\phi_{1}^{2} \ldots \phi_{M}^{2}}=1$, where $\phi_{1}$ to $\phi_{M}$ are elements of $\varphi(z)_{m}$. Similar expressions exist for the component of horizontal velocity, $v$, normal to $u$ and for the vertical velocity, $w$. Kundu et al. (1975) gave a detailed discussion of the method and showed that $\lambda_{m}$ is proportional to the energy in mode $m$. The modes are ranked in order of decreasing energy, with mode 1 being the largest, and the motion can be succinctly summarised if it is dominated by just a few modes.

The results are presented in Fig. 8 and Table 1. The data were high pass filtered to exclude frequencies below 1 c.p.h. before being analysed. In general over $90 \%$ of all energy was contained
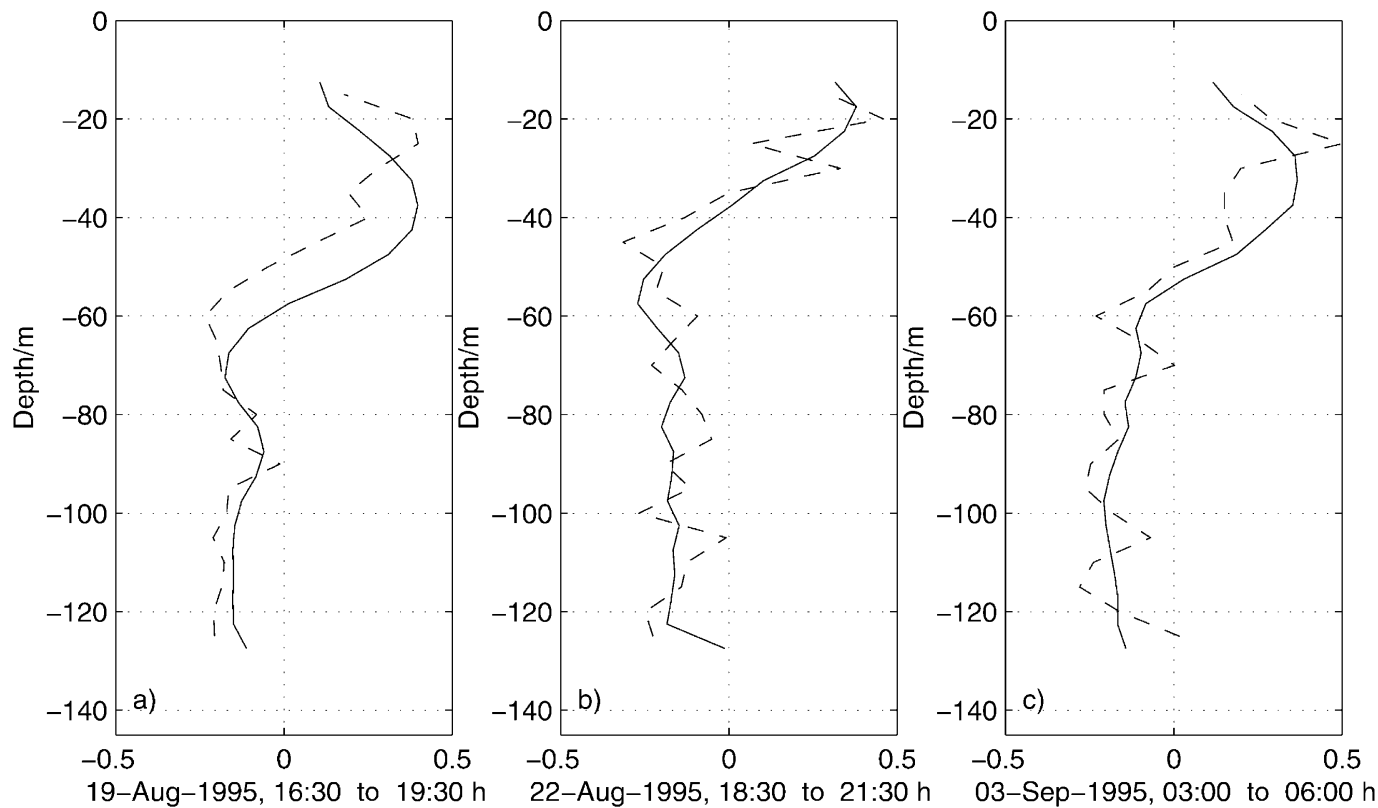

Fig. 8. Empirical mode 1 derived from observations that have been highpass filtered above $1 \mathrm{~h}$. Plain line-the horizontal velocity mode; dashed line - derivative of the vertical velocity $(\partial w / \partial z)$ mode. (a) 19 August, (b) 22 August, (c) 3 September.

Table 1

Percentage variance in the first three high frequency empirical orthogonal modes for the three hours of records depicted in Figs. 4-6

\begin{tabular}{lccc}
\hline Mode no. & 19 August & 22 August & 3 September \\
\hline Vertical velocity & & & \\
1 & 95 & 93 & 60 \\
2 & 2 & 3 & 74 \\
Horizontal velocity & 85 & 73 & 15 \\
1 & 6 & 17 & \\
2 & & & \\
\hline
\end{tabular}


in the first two modes, although there was more mode 2 activity in the horizontal velocities than in their vertical counterparts. In most wave packets the first mode $u$ and $\partial w / \partial z$ eigenvectors were very similar, after allowing for computational noise. The relationship can be clearly seen for all three examples, but particularly on 19 August (Fig. 8a) where a small increase in velocity at about $85 \mathrm{~m}$ is reproduced in both curves. However it is noticeable here, and in a number of other examples, that in the region of highest shear the $\partial w / \partial z$ eigenvector was up to $10 \mathrm{~m}$ shallower than its $u$ counterpart.

The empirical velocity mode on 19 August (Fig. 8a) compares better with the baroclinic mode computed during the passage of the waves (Fig. 7d), when the thermocline was depressed, than with that derived before their arrival (Fig. 7b). This may be because the kinetic energy in the waves was greatest at that time. In general, the empirical mode has the maximum shear at a deeper level and a more convoluted shape than the baroclinic modes.

In summary, the observations seem to be close enough to that which might be expected from linear dynamics and continuity, to allow a more detailed analysis.

\section{Computation of the observed and theoretical transports}

In order to compute Eq. (7) it is necessary to define the vertical displacement of the interface $\left(H_{2}+\xi\right)$ and determine the average velocities in the layers above and below it. The shape of the empirical eigenvectors and the relative size of the layer suggest that the error due to vertical shear near the seabed in the lower layer is likely to be less than that due to shear near the surface in the upper layer. For this reason, and for brevity, only the lower layer observed transport is considered, i.e.

$$
\tilde{Q}_{2}=\int_{0}^{z_{0}} u^{\prime}(z) \partial z,
$$

where $z_{0}=H_{2}+\xi$ and $u^{\prime}(z)$ is the velocity anomaly in the direction of wave propagation (i.e. velocity minus its depth mean) and should contain mainly baroclinic motion.

\subsection{Determination of the interface depth}

Since the vertical and horizontal empirical modes are consistent it should be possible to determine $z_{0}$ using the horizontal currents, although one could equally use the vertical velocities. We prefer to define $z_{0}$ as the depth at which $u^{\prime}$ is zero because, so long as there is only a single crossing point, the flux above it will match an equal and opposite flux below it. This definition thus satisfies one of the assumptions of Eq. (7). However, the approach introduces problems in calculating the true depth averaged flow in the direction of propagation, $U$, determining an appropriate velocity anomaly direction, and handling multiple crossing points. These problems are considered below.

The importance of an accurate determination of $U$ can be easily demonstrated. Suppose that the full velocity profile, $u(z)$, is given by

$$
u(z)=U+u^{\prime}(z) .
$$


For a zero crossing point, $u^{\prime}\left(z_{0}\right)=0$, i.e.

$$
u\left(z_{0}\right)=U .
$$

Although $u(z)$ is measured directly, $U$ must be calculated by averaging $u(z)$ over the water column. However, as discussed below, there may be an error in this estimate $\left(U_{\mathrm{E}}\right)$. There will then be an error in the estimate of $z_{0}, \delta$, given by

$$
u\left(z_{0}+\delta\right)=U+U_{\mathrm{E}} .
$$

If $\delta$ is assumed to be small, then expanding Eq. (15) as a Taylor series and subtracting (14) gives

$$
\delta=\frac{U_{\mathrm{E}}}{\mathrm{d} u / \mathrm{d} z} .
$$

Thus, so long as the vertical gradient of horizontal velocity is large any error in the estimate of $z_{0}$ will be small.

In practice, the time series of zero crossing points, $z_{0}(t)$, was found as follows. The vertical shear between the upper and lower layers $(7.5-33.5 \mathrm{~m}$ and $67.5-102.5 \mathrm{~m}$, respectively), $\Delta u(t)$, was calculated and smoothed with a cut-off period of $5 \mathrm{~min}$. The barotropic velocity (averaged between 7.5 and $127.5 \mathrm{~m}$ ) was smoothed with a cut off period of $3 \mathrm{~h}$ and subtracted from $u(z, t)$ to give $u^{\prime}(z, t)$, which was further smoothed vertically with a cut-off length of about $20 \mathrm{~m} . z_{0}(t)$ was then found for the component of $u^{\prime}(z, t)$ parallel to $\Delta u(t)$ by linear interpolation. Occasionally, when two or more zero crossings were encountered, the one closest to the mean $z_{0}$ of the preceding $12.4 \mathrm{~h}$ was selected.

\subsection{Calculation of the observed lower layer transport}

The observed lower layer transport was calculated as

$$
\tilde{Q}_{2}(t)=\frac{z_{0}(t)}{\left(z_{0}(t)-15\right)} \int_{15}^{z_{0}(t)}\left(u^{\prime}(z, t)-\hat{u}_{2}\right) \partial z
$$

(rather than that suggested by Eq. (12)), where $\hat{u}_{2}$ the background low frequency velocity anomaly in the lower layer, probably due to the internal tide (see e.g. 3 September, Fig. 6). Its amplitude was defined as the mean flow in the lower layer during the 30 min preceding the arrival of a NIW packet. The scaling and limits of the integral are needed in Eq. (17) because the ADCP did not measure the currents within $15 \mathrm{~m}$ of the seabed.

\subsection{Calculation of the theoretical lower layer transport}

Several variables in Eq. (7) need to be specified in order to calculate the theoretical transport, $Q_{2}$. The undisturbed depth of the lower layer, $H_{2}$, was defined as the average of $z_{0}(t)$ over the 30 min preceding the arrival of the wave packet. Thus $\xi(t)=z_{0}(t)-H_{2}$, and $H_{1}=145-H_{2}$. We are dealing with high frequency waves, so the phase speed for linear long waves, $C_{0}=\sigma / k$ was derived from the first baroclinic mode of

$$
\frac{\mathrm{d}^{2} w}{\mathrm{~d} z^{2}}+\frac{N^{2}}{\sigma^{2}} k^{2} w=0
$$


(i.e. the non-dispersive version of Eq. (9)). Density profiles from CTD casts taken on the shelf during the period of the ADCP deployment gave a mean value for $C_{0}$ of $0.54 \pm 0.02 \mathrm{~m} \mathrm{~s}^{-1}$.

The mean barotropic velocity can affect the apparent shape of the wave and bias estimates of $\partial^{2} / \partial t^{2}$ in the dispersion term. Two points on a wave that are separated by a distance of $\Delta x$ will pass the current meter at an interval given by

$$
\Delta x=\left(C_{0}+U\right) \Delta t^{\prime}=C_{0} \Delta t,
$$

where $\Delta t$ is the interval that would have been observed in the absence of a barotropic current; and $\Delta t^{\prime}$ is the observed interval. Thus a typical large value for $U$ (about $0.2 \mathrm{~m} \mathrm{~s}^{-1}$ ) could alter the size of the dispersion term by a factor of about two. This effect was accounted for in the calculations although it was not very important because the dispersion term was always small.

\subsection{Analysis of a wave packet}

The zero-crossing method for determining $z_{0}(t)$ worked well with large and well-defined waves and on such occasions Eq. (7) provided a useful insight into NIW dynamics. A good example is the packet of large $(\varepsilon \approx 1)$ waves observed on 19 August when the $Q_{2}$ and $\tilde{Q}_{2}$ transports were very similar (Fig. 9b). The linear term in $Q_{2}$ made the biggest contribution to the total transport in the leading wave $(\sim 70 \%)$ with the non-linear term accounting for most of the remaining $30 \%$ (Fig. 9c). (The non-linear term contributed slightly more, $40 \%$, to $U_{2}$.) The surprising result is that the dispersion term is negligible at all times, and therefore does not balance the non-linear term as would be the case if the waves were $\mathrm{KdV}$ solitons.

\subsection{Expected observational errors}

The observational errors fall into two categories, depending on whether they effect the direct observation of transport, $\tilde{Q}_{2}$, or the theoretical transport determined from the observed interface displacement, $Q_{2}$.

Errors in $\tilde{Q}_{2}$ are most likely due to the estimate of $\hat{u}_{2}$ and the linear extrapolation of the integral from $15 \mathrm{~m}$ to the seabed:

- The background velocity, $\hat{u}_{2}$, was typically $0.02-0.04 \mathrm{~m} \mathrm{~s}^{-1}$. The ADCP reported a random error of $\pm 0.014 \mathrm{~m} \mathrm{~s}^{-1}$ in each bin during the observation period, so the barotropic current, averaged over 25 bins, should have a random error of about $\pm 0.003 \mathrm{~m} \mathrm{~s}^{-1}$. Assuming $z_{0}=115 \mathrm{~m}$, then a systematic error of this magnitude would result in an error of up to $\pm 0.3 \mathrm{~m}^{2} \mathrm{~s}^{-1}$, or about $6 \%$ of the mean $<\tilde{Q}_{2}>$ (see Table 2 ).

- The velocity anomaly, $u^{\prime}, 15 \mathrm{~m}$ above the seabed should be of order $u^{\prime}(15)=1 / 100 \int_{15}^{115} u^{\prime}(z) \mathrm{d} z$. The speed at the seabed, $u^{\prime}(0)$, is unknown, but for error analysis purposes can be assumed to have been in the range $\left[0,2 u^{\prime}(15)\right]$. These two assumptions suggest that $\tilde{Q}_{2}$ is in the range $u^{\prime}(15) \cdot(115 \pm 15 / 2)$. If $u^{\prime}(0)$ was uniformly distributed between 0 and $2 u^{\prime}(15)$ then the standard deviation of $\tilde{Q}_{2}$ should be about $4 \%$. 

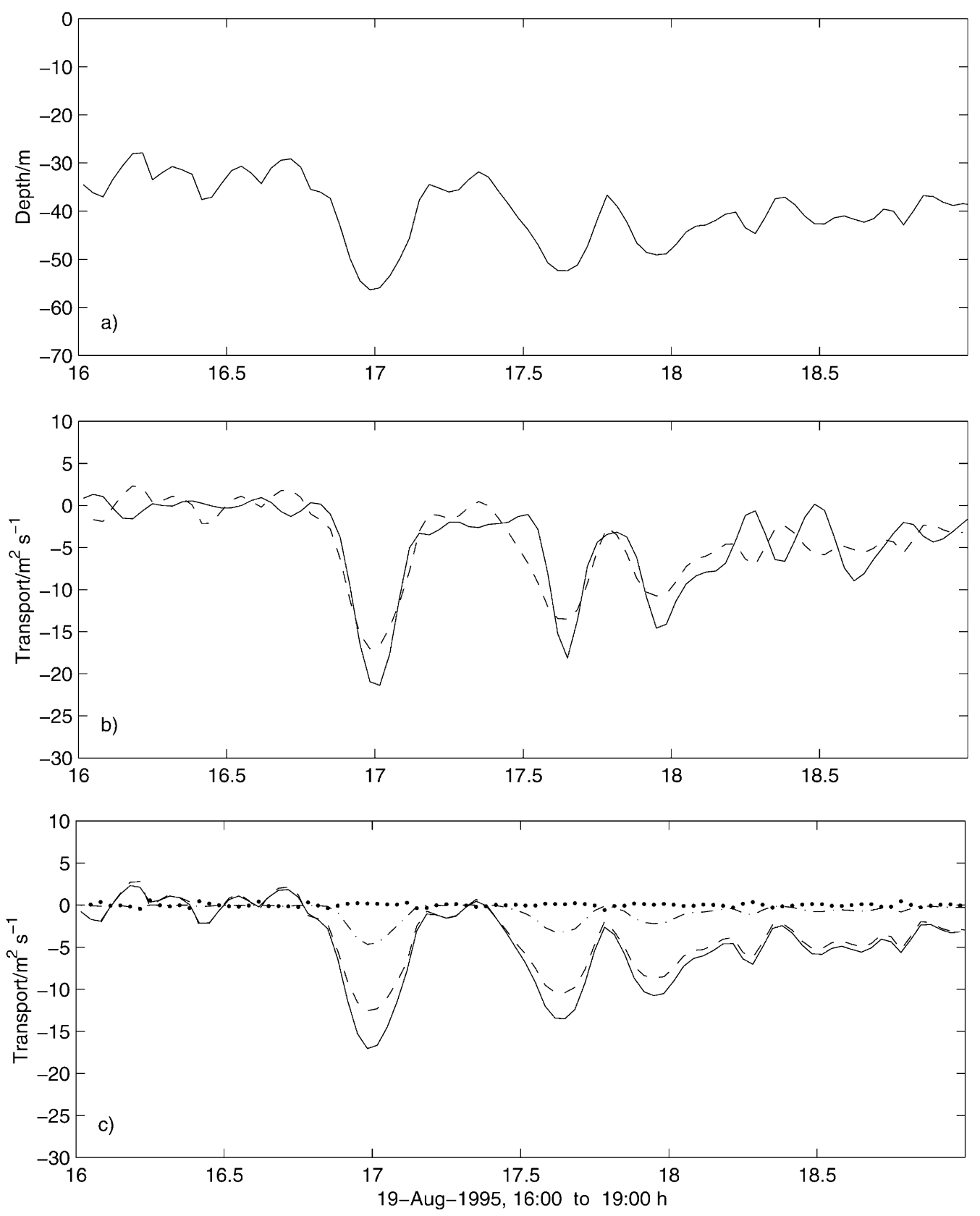

Fig. 9. (a) Depth of the interface, $z_{0}$, on 19 August, (b) observed transport, $\tilde{Q}_{2}$, (plain line) and predicted transport, $Q_{2}$, (dashed line), (c) the various terms of the theoretical transport-total (plain line); linear term (dashed line); non-linear term (dot-dashed line); dispersion term (dotted line). 
Table 2

The theoretical, $\left\langle Q_{2}\right\rangle$, and observed, $\left\langle\tilde{Q}_{2}\right\rangle$, transport averaged over 34 individual NIWs in $\mathrm{m}^{2} \mathrm{~s}^{-1}$

\begin{tabular}{lllcl}
\hline & Average & S.D. & Maximum & Minimum \\
\hline$\left\langle\tilde{Q}_{2}\right\rangle$ & 4.7 & 2.2 & 9.7 & 1.4 \\
$\left\langle Q_{2}\right\rangle$ & 5.0 & 2.4 & 10.6 & 1.9 \\
\hline
\end{tabular}

Errors in $Q_{2}$ are likely to be derived from the estimates of $C_{0}, z_{0}$ and $H_{2}$, as well as limitations in the theory. Their effect on the dispersion term, which was small in all cases, has been ignored.

- The phase speed $\left(C_{0}\right)$ contributes linearly to $Q_{2}$ and, as reported above, had a standard deviation of $4 \%$.

- Errors in $\mathrm{H}_{2}$ affect the size of the non-linear term in Eq. (7) directly, but could also affect the size of $\xi$ since $\xi=z_{0}-H_{2}$. If $H_{2}$ was about $115 \mathrm{~m}$ and had an error of $\Delta_{H}$ then the size of the resulting error in the non-linear term would be about $\Delta_{H} / 17$. From the observations, the nonlinear term contributed at most $30 \%$ to $Q_{2}$, so the error in Eq. (7) was about $2 \%$ when $\Delta_{H}$ was $1 \mathrm{~m}$ and $11 \%$ when it was $6 \mathrm{~m}$.

- If $\delta$, the error in $\xi$ is small then it can easily be shown from Eq. (7) that

$$
\frac{Q_{\mathrm{E}}}{Q_{2}}=\frac{\delta}{\xi},
$$

where $Q_{\mathrm{E}}$ is the error in $Q_{2}$. Assuming that $\delta$ and $\xi$ were uniformly distributed between $\pm \Delta$ and $\left[\xi_{1}, \xi_{2}\right]$ respectively in the observations, then their mean error would be 0 and the standard deviation $\Delta / \sqrt{3 \xi_{1} \xi_{2}}$. With the exception of two small waves $(\varepsilon<0.2$, Fig. 10), $\xi$ was uniformly distributed between $\xi_{1}=8$ and $\xi_{2}=37 \mathrm{~m}$, so its standard deviation should be about $\Delta / 30$. The main reason for $\delta$ (see 16), was the existence of errors in $U_{\mathrm{E}}$, the depth mean velocity, due to the fact that the ADCP could not measure the current in the both the top $10 \mathrm{~m}$ and the bottom $15 \mathrm{~m}$ of the water column. A typical value for $\mathrm{d} u / \mathrm{d} z$ in the NIWs was $1 / 645 \mathrm{~s}^{-1}\left(0.1 \mathrm{~m} \mathrm{~s}^{-1}\right.$ in $\left.64.5 \mathrm{~m}\right)$, so if $U_{\mathrm{E}}$ was uniformly distributed in the range $\pm 0.005 \mathrm{~m} \mathrm{~s}^{-1}$ (which seems a reasonable assumption) then $\Delta$ would be $3 \mathrm{~m}$. From Eq. (20) the standard deviation due to this error would thus be $3 / 30$, or $10 \%$.

The significance of these errors will be considered in the next section.

\section{A comparison of all large waves}

It was possible to identify a total of 34 individual NIWs in the observations and the transport in each of them was estimated from the observations of velocity, $\left\langle\tilde{Q}_{2}\right\rangle$, and predicted from the observations of interface elevation using Eq. (7), $\left\langle Q_{2}\right\rangle$. (The angle brackets indicate the temporal average over a single wave.) These waves had an mean observed transport of $4.7 \mathrm{~m}^{2} \mathrm{~s}^{-1}$ with a standard deviation of $2.2 \mathrm{~m}^{2} \mathrm{~s}^{-1}$ (Table 2). Taken together the statistics of $\left\langle\tilde{Q}_{2}\right\rangle$ and $\left\langle Q_{2}\right\rangle$ agree exceptionally well, with the mean predicted transport $\left(5.0 \mathrm{~m}^{2} \mathrm{~s}^{-1}\right)$ only $6 \%$ greater than that observed, and standard deviation in the predictions almost identical to that of the observations. 


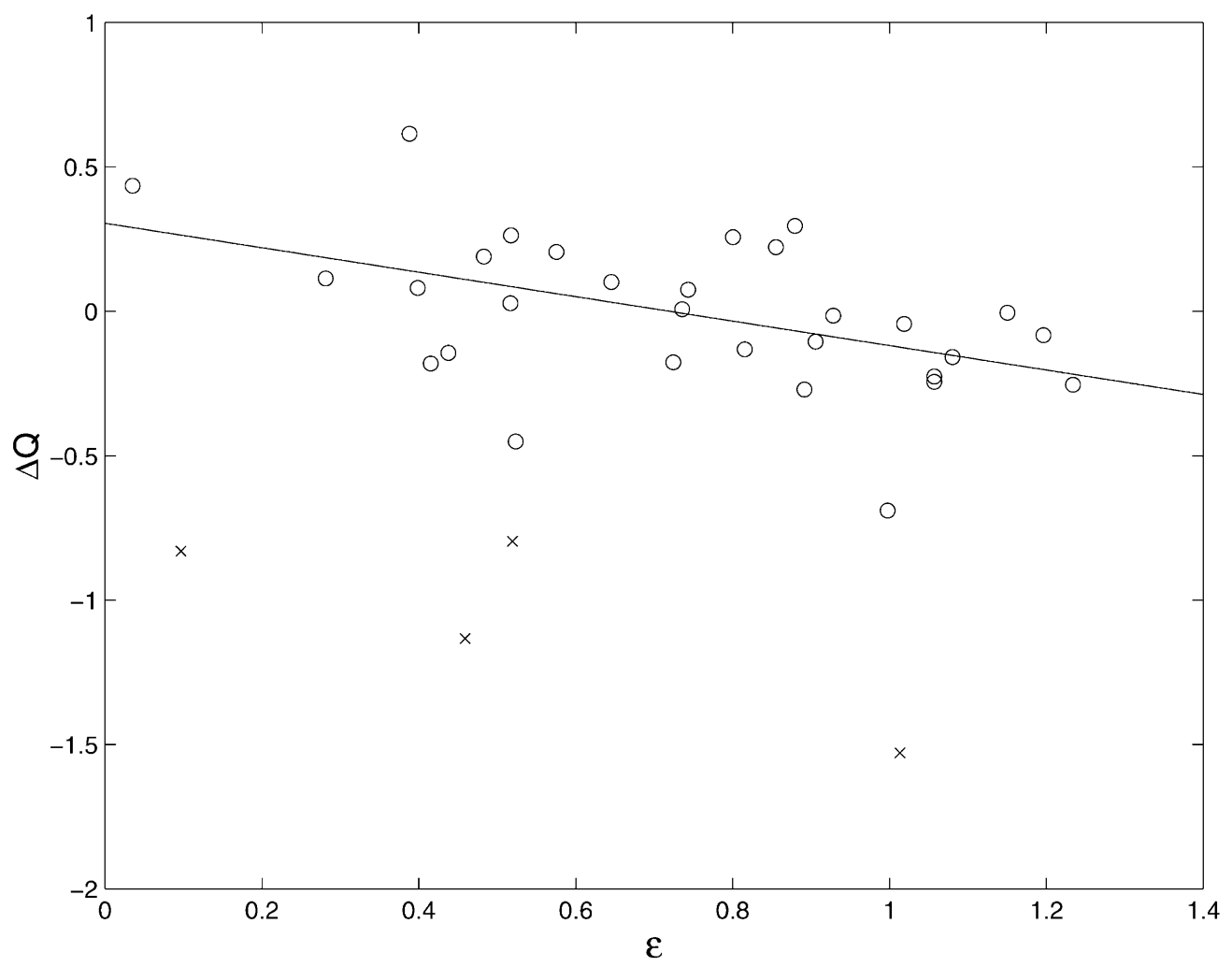

Fig. 10. Comparison of the normalised transport error $\Delta Q$ as a function of non-linearity, $\varepsilon$, for 34 waves. ' $\times$ ' indicates observations that have been excluded from the calculation of the regression line, which is shown. Eq. (7) appears to over predict transport at high values of $\varepsilon$.

Maximum and minimum transports were also very similar. Since the non-linearity of the waves, $\varepsilon$, ranged from 0.17 to 1.25 these results suggest that Eq. (7) is a good estimate of the transport in a typical NIW.

When individual waves are ranked by size the results cluster about the line $\left\langle\tilde{Q}_{2}\right\rangle=-1.1+$ $0.73\left\langle Q_{2}\right\rangle$ with a standard deviation of $1.3 \mathrm{~m}^{2} \mathrm{~s}^{-1}$, or $26 \%$ of the mean $\left\langle Q_{2}\right\rangle\left(5.0 \mathrm{~m}^{2} \mathrm{~s}^{-1}\right.$, Table 2). Exact agreement occurs when $\left\langle Q_{2}\right\rangle=4.1 \mathrm{~m}^{2} \mathrm{~s}^{-1}$. More generally the trend can be expressed in terms of the normalised transport error, $\Delta Q \equiv\left(\left\langle\tilde{Q}_{2}\right\rangle-\left\langle Q_{2}\right\rangle\right) /\left\langle\tilde{Q}_{2}\right\rangle$. Ignoring four anomalous values, for which $|\Delta Q| \tilde{>} 0.5$, the relationship is $\Delta Q=0.31-0.42 \varepsilon$ with a standard deviation of $0.23(23 \%$, Fig. 10). For small values of $\varepsilon$, the theoretical values are about $20 \%$ too small, whilst for $\varepsilon$ of order 1 and above they are about $10 \%$ too high. Eq. (7) was exact for $\varepsilon=0.74$.

An examination of the trend in the data is beyond the scope of this work. Tests suggest that only a small part of the slope can be attributed to signal attenuation by time averaging or the horizontal separation of the sound paths of the ADCP, when averaged over a wave.

The sum of the variance of the expected observational errors suggests that the standard deviation of the error in the observed transport, $\tilde{Q}_{2}$, was about $7 \%$, whilst that of the theoretical transport, $Q_{2}$, was about $12 \%$. This gives a total expected error for the whole data set of roughly $14 \%$. The standard deviation of the difference between this error and that observed $(23 \%)$ can be 
attributed to inaccuracy in the theory, for example due to its simplifying assumptions, and is only about $18 \%$.

\section{Discussion}

Eqs. (7) and (8) provide a simple method for determining the horizontal mass transport and velocity in packets of NIWs propagating onto a shelf where only the vertical displacement (or velocity) is known. When averaged over 19 days, and for a wide range of wave sizes, the observed and theoretical mean transports per wave were almost identical (Table 2). There thus appears to be no bias in the theory. Given the size of the expected observational errors, the mean error per wave, estimated as the difference between the observed transport and that predicted from the vertical displacement of the interface, was small. We suggest that in shelf regions where there is clear evidence of on-shore propagating NIWs it should be possible to use Eq. (7) to estimate $\left\langle Q_{2}\right\rangle$ from thermistor chain data, for example, if over 30 waves are used and the maximum $\varepsilon$ per wave is typically in the range $[0.25,1.25]$.

One advantage of a thermistor chain over an ADCP (apart from the cost) is that $C_{0}$ can be recalculated as it evolves in time, rather than assumed constant as here. However, care should be taken with such data to ensure that an appropriate isotherm (such as at the level of the zero crossing point of the lowest baroclinic velocity mode) is used to trace the movement of the interface and give $\mathrm{H}_{2}$ and $z_{0}$. Furthermore, unless local current meter data are available it will not be possible to remove Doppler shifts due to barotropic currents, although in some places estimates of the tidal impact may be inferred from model predictions. Unfortunately thermistor chain data cannot be used to infer the direction of wave, or energy, propagation. For this purpose some other form of measurement, for example satellite SAR imaging or current meters, are required.

At first sight it might seem surprising that individual NIWs contribute a large mass transport given that their period and duration are small. Our analysis has shown that it is because they are waves of depression only, so that the linear term can integrate to a larger quantity than the nonlinear one. In an harmonic wave, by contrast, the integral (over a wave period) of the linear term is zero and its mass transport derived from the integration of the non-linear term. The integral of the dispersion term is zero for both harmonic waves and NIWs.

The observations have illustrated three important points about NIWs on the Malin Shelf, namely that

(i) their amplitude in particular was not closely linked to the semi-diurnal barotropic tide, as might have been expected from theory,

(ii) their direction of propagation appeared to be more southward than expected-i.e. they did not propagate normal to the shelf edge, and

(iii) there was significant variability in the horizontal velocity profile of the different wave packets which, although dominated by mode 1 , had a different shape to the lowest baroclinic mode.

It is not intended to pursue the first point in detail here, except to note that tidal generation theory implies that NIWs should be larger on spring tides than on neaps, unlike the case here. It 
may be significant that the period of low NIW activity occurred when there was quite a strong southward current on the shelf (see Fig. 3). This flow may have been accompanied by a change in stratification that made the slope region sub-critical which, from internal tide generation theory (e.g. Craig, 1987), could have significantly reduced the amplitude of the internal tide. Alternatively, the wave front may not have been particularly extensive and that although NIWs were being continually formed at the shelf edge, external factors meant that they did not always pass Sta. S140. It is also noted that Small et al. (1999a) reported an internal wave propagating over the shelf edge from the Rockall Trough to the north west of Sta. S140. Some of the waves, at least, may have come from the ocean.

An oceanic source could explain the apparent south-eastward propagation direction of the waves whose origin was undoubtedly to the west of Sta. S140. The observations challenge conventional two-dimensional theory of tidal generation (e.g. Maxworthy, 1979, Gerkema, 1996), which predicts that they should have emerged from shelf break and propagated in a direction of $100^{\circ} \mathrm{T}$, normal to it, rather than the variety of directions that were observed. A three-dimensional tidal model of the area by Xing and Davies (1998) has strong south-eastward surface internal tidal currents at Sta. S140 during part of the tidal cycle, which suggests that this deviation may be a local effect. In addition, the phase of the waves seems to be only loosely linked to that of the local barotropic tide. Nevertheless, it is noticeable that in many packets successive waves turned anticyclonically at a rate that was similar to the change in phase of the internal tide. It therefore seems likely that the two were correlated.

However, we are not concerned here with the origin of the waves, so much as in their form and contribution to local mass transport. The empirical horizontal velocity modal shapes were often convoluted (Fig. 7) and varied between individual wave packets. Individual baroclinic and empirical eigenvectors were not particularly similar on 19 August. The discrepancy may indicate that the waves were not freely propagating, or that they comprised two or more baroclinic modes. The first idea is preferred because the waves dissipated energy by mixing (see Inall et al., 2000), which may have been simultaneously replenished from the internal tide. Furthermore, the observed non-linear term was much larger than the dispersion term, which precludes the possibility that they were simple KdV solitons.

Although it is possible to quantify the transport due to the NIWs it is more difficult to assess their importance in relation to the local internal tide, which had much larger oscillating on-shore and off-shore transports that were not easy to determine accurately. Notable NIWs were only observed during about half of the observed tidal cycles at Sta. S140 and, when present, contributed about $5 \mathrm{~m}^{2} \mathrm{~s}^{-1}$ to exchange over a period of typically $1.5 \mathrm{~h}$. (This ignores the fact that the waves did not propagate exactly normal to the shelf edge). This figure translates into a smaller sustained transport than the $1 \mathrm{~m}^{2} \mathrm{~s}^{-1}$ estimated by Huthnance (1995) for a generalised NIW, but is nevertheless comparable to other shelf edge processes. The average volume transported offshore in the lower layer per tidal cycle by a typical packet of NIWs was about $2.7 \times 10^{4} \mathrm{~m}^{3}$ per unit length of crest (or $0.6 \mathrm{~m}^{2} \mathrm{~s}^{-1}$ ). By contrast it is estimated from Eq. (7) that the trough of a typical $10 \mathrm{~m}$ amplitude sinusoidal internal tide passing Sta. S140 would transport nearly an order of magnitude more water offshore (about $1.6 \times 10^{5} \mathrm{~m}^{3}$ ). The net flux over a tidal cycle can be attributed to any non-linearity in the internal tide and it is not possible to say whether, in reality, the NIW contribution is part of this flux or whether it should be added to it. In part the answer depends on the origin of the NIWs. Furthermore, if they are independent of the local internal tide 
they may be a source of net transport, above and below the thermocline; if not then their contribution may be largely cancelled out by the return tidal flow.

\section{Conclusions}

Huthnance (1995) suggested that NIWs may contribute significantly to cross-shelf exchanges in some locations. This idea has been investigated using ADCP current meter observations to estimate horizontal fluxes (i) directly from the horizontal currents, and (ii) by inference from the vertical displacement of the interface. The latter approach used a KdV type theory of NIW propagation based on a linear (rather than non-linear) phase speed. Both methods gave consistent results. On the Malin Shelf, the offshore transport in the lower layer due to sporadic packets of large amplitude NIWs was about $5 \mathrm{~m}^{2} \mathrm{~s}^{-1}$. Large NIWs were only observed on about half of all tidal cycles, so this short lived transport translates into a sustained rate over the whole deployment period of about $0.3 \mathrm{~m}^{2} \mathrm{~s}^{-1}$. This rate is smaller than the typical value of $1 \mathrm{~m}^{2} \mathrm{~s}^{-1}$ suggested for regions with large internal tides by Huthnance. However a relatively small flux is not surprising given that the internal tide on the Malin Shelf is not particularly large (Sherwin, 1988). It is important to note that the dispersion term in the waves was much smaller than the non-linear term so the waves could not be described as $\mathrm{KdV}$ solitons. In locations where only high frequency thermistor chain data are available, Eq. (7) can be used to provide valuable information on the cross shelf fluxes of water. The method can also be used for assessing the fluxes of dissolved matter when the concentration is known.

\section{Acknowledgements}

We thank the officers and crew on board RRS Challenger and staff from the University of Wales, Bangor and CCMS-POL, Bidston who maintained the mooring. The work was carried out with the support of NERC (LOIS/SES grant GST/02/764), the Procurement Executive (MOD), and INTAS and RFBR grants (RFBR-INTAS 95-969 and RFBR 97-07-65635).

\section{References}

Barenblatt, G.I., Ivanov, M.Ya., Shapiro, G.I., 1985. On the structure of wave fronts in non-linear dissipative media. Archive for Rational Mechanics and Analysis 87 (4), 293-303.

Craig, P.D., 1987. Solutions for internal tidal generation over coastal topography. Journal of Marine Research 45, 83-105.

da Silva, J.C., Jeans, D.R.G., Robinson, I.S., Sherwin, T.J., 1997. The application of near real-time ERS-1 SAR data to the location of internal waves at sea. International Journal of Remote Sensing 18, 3507-3517.

Gerkema, T., 1996. A unified model for the generation and fission of internal tides in a rotating ocean. Journal of Marine Research 54, 421-450.

Halpern, D., 1971. Observations of short period internal waves in Massachusetts Bay. Journal of Marine Research 29, $116-132$.

Heathershaw, A.D., 1985. Observations of internal wave current fluctuations at the shelf-edge and their implications for sediment transport. Continental Shelf Research 4, 485-493. 
Holloway, P.E., Pelinovsky, E., Talipova, T., 1999. A generalised Korteveg-de Vries model of internal tide transformation in the coastal zone. Journal of Geophysical Research 104, 18,333-18,350.

Huthnance, J.M., 1995. Circulation, exchange and water masses at the ocean margin: the role of physical processes at the shelf edge. Progress in Oceanography 35, 353-431.

Inall, M.E., Rippeth, T.P., Sherwin, T.J., 2000. The impact of non-linear internal waves on the dissipation of internal tidal energy near a shelf edge. Journal of Geophysical Research 105, 8687-8705.

Jeans, D.R.G., Sherwin, T.J., 2001. The variability of strongly non-linear solitary internal waves observed during an upwelling season on the Portuguese Shelf. Continental Shelf Research, in press.

Kao, T.W., Pan, F.-S., Renouard, D., 1985. Internal solitons on the pycnocline: generation, propagaion, and shoaling and breaking over a slope. Journal of Fluid Mechanics 159, 19-53.

Konyaev, K.V., Sabinin, K.D., 1992. Waves inside the ocean. Gidrometeoizdat, SPb, 272pp (in Russian).

Kundu, P.K., Allen, J.S., Smith, R.L., 1975. Modal decomposition of the velocity field near the Oregon coast. Journal of Physical Oceanography 5, 683-704.

Maxworthy, T., 1979. A note on the internal solitary waves produced by tidal flow over a three dimensional ridge. Journal of Geophysical Research 84, 338-346.

Morgan, P.P., 1994. SEAWATER: a library of MATLAB computational routines for the properties of sea water. CSIRO Marine Laboratories Report 22, 29pp.

New, A.L., Pingree, R.D., 1992. Local generation of internal soliton packets in the central bay of Biscay. Deep-Sea Research 39A, 1521-1534.

Ostrovsky, L.A., Stepanyants, Y.A., 1989. Do internal solitons exist in the ocean? Reviews of Geophysics 27, $293-310$.

Phillips, O.M., 1977. The Dynamics of the Upper Ocean. Cambridge University Press, Cambridge, 336 pp.

Renouard, D.P., Zhang, X., 1989. Baroclinic wave generation by barotropic waves passing over a shelf. Dynamics of Atmospheres and Oceans 13, 123-148.

Sandstrom, H., Elliott, J.A., 1984. Internal tide and solitons on the Scotian Shelf: a nutrient pump at work. Journal of Geophysical Research 89 (C4), 473-480.

Sandstrom, H., Oakey, N.S., 1995. Dissipation in internal tides and solitary waves. Journal of Physical Oceanography $25,604-614$.

Sherwin, T.J., 1988. Analysis of an internal tide observed on the Malin shelf, north of Ireland. Journal of Physical Oceanography $18,1035-1050$.

Sherwin, T.J., Taylor, N., 1990. Numerical investigations of linear internal tide generation in the Rockall trough. DeepSea Research 37, 1595-1618.

Small, J., Hallock, Z., Pavey, G., Scott, J., 1999a. Observations of large amplitude internal waves at the Malin Shelf edge during SESAME 1995. Continental Shelf Research 19, 1389-1436.

Small, J., Sawyer, T.C., Scott, J.C., 1999b. The evolution of an internal bore at the Malin shelf break. Annales Geophysicae 17, 547-565.

Walker, S.A., Martin, A.J., Easson, W.J., 1998. Velocity fields in solitary internal waves. Proceedings of the Eighth International Offshore and Polar Engineering Conference, Montreal, Canada.

Xing, J., Davies, A.M., 1998. A three-dimensional model of internal tides on the Malin-Hebrides shelf and shelf edge. Journal of Geophysical Research 103 (C12), 27,821-27,847. 